\title{
A Questionnaire for Assessment of Healthy Living Aspect of Physical Education for Secondary School Children: Initial Development and Validation
}

\author{
Pankaja Pandey ${ }^{1}$ and Kalpana Sharma ${ }^{2}$ \\ ${ }^{1} \mathrm{Ph}$. D Scholar, ASPESS, Amity University, Noida (India) \\ ${ }^{2}$ Professor, Supervisor \& Director, ASPESS, Amity University, Noida (India)
}

\section{ABSTRACT}

Physical education provides a scientific base of knowledge to the children which combines biological, physical, environmental and social studies. The shortage of efficient steps to show the value of physical education in learner growth is a grave problem for the future of the discipline in this era of enhanced transparency (Lund \& Kirk, 2010). Based on the curriculum guidelines for assessment in Physical education, there are four aspects, viz., physical fitness, sports skill, healthy living and neuromuscular co-ordination, to assess the efficacy of physical education programs. This paper establishes and validates an instrument for assessing the healthy living aspect. Following the goals of the National Curriculum System Physical Education Policy, the first edition of the statements was prepared. The instrument components were objectively evaluated through professional judgment $(n=10)$ to ensure the high consistency, validity and understandability of the claims and proper association of characteristics. The exceptional findings of the pilot test (n $=600$ ) strengthened the curricular framework and confirmed the quality and efficacy of the questionnaire. Exploratory factor analysis revealed a number of statements that were in accordance with the initial methodology and a connection between the factors and the assertion was sufficient for the confirmatory factor analysis. Fitting indices show that the conclusions coincided well with the questionnaire and also Pearson correlated test corroborated positive, important correlations by the suggested variables. The questionnaire has also demonstrated strong outcomes and has the ability to determine the knowledge of healthy living aspect learnt through physical education in secondary school childrens.

\section{KEY WORDS: HEALTHY LIVING, PHYSICAL EDUCATION ASSESSMENT, QUESTIONNAIRE VALIDATION AND DEVELOPMENT.}

\section{INTRODUCTION}

For physical education programmes to be successful, the curriculum plays an important role. Focus on the curriculum for physical education is vital because a major problem is that students do not understand and appreciate

\section{ARTICLE INFORMATION}

*Corresponding Author: pankaja.panky@gmail.com Received 20th Oct 2020 Accepted after revision 15th Dec 2020 Print ISSN: 0974-6455 Online ISSN: 2321-4007 CODEN: BBRCBA

Thomson Reuters ISI Web of Science Clarivate Analytics USA and Crossref Indexed Journal

\section{Clarivate
Analytics}

NAAS Journal Score 2020 (4.31)

A Society of Science and Nature Publication,

Bhopal India 2020. All rights reserved.

Online Contents Available at: http//www.bbrc.in/

Doi: $h t t p: / / d x$.doi.org/10.21786/bbrc/13.15/3 the impact of physical education on other faculties not just during the learning phase but all through the life. Hennessy (1996) cites an example of the fact that the knowledge of algebra which a student acquired in the school might not be used later in day to day life, however, there exists endless use of the hand-eye coordination and the slightly bigger lung capacity which resulted from the participation in physical education programmes.

One of the aims of physical education is to educate students to be involved physically. Physical education helps prevent sedentary lifestyle in students by teaching skills, values, and common knowledge about physical exercises. Students are taught the healthy ways of life. They are also taught how to take care of their personal 
health. Physical education also has preventive health benefits for the students. Majority of the health problems can be prevented by physical exercises and the discipline which is imparted by physical education. Obesity, which is now considered a global endemic, can be controlled and surmounted through proper physical education programmes. Another goal of physical education is to help make learning fun.

Using sports to involve the students in the learning process accelerates their development. Use of sports to help in the personal growth of students is a very effective mechanism. For example, improvements in the emotional and communication skills of a student can be very effective through sports. Physical education also instils the values of teamwork and coordination. Yet another goal of physical education is to ensure the inclusion of those students who are typically excluded from the society based on social class, gender and disability. Kidd and Donnelly (2000) demonstrated the need for a physical education programme which ensure girls achieve the parity of esteem. Donnelly (2008) highlights the fact that "poverty is the single greatest barrier to participation" in the context of sports. Physical activities help enhance health, self-efficacy, and community inclusion of persons with disabilities (Moss, Landon \& Fleming, 2017)

Ensuring a holistic curriculum for physical education requires an effective assessment of the same. Evaluation is a learning method for pupils, instructors, parents and policy-makers in physical education. The aim of Veal (1995) was to offer guidance to both learners and teachers while evaluation is part of the teaching and learning stage of practice; the key goal of the appraisal." Anderson \&t Goode (1997) describe assessment as a "three-way connection between teaching, testing, and learning."

Healthy Living Aspect in Physical Education: We are living through an era in which overweight and obesity have become a major global health problem, particularly among children and young adults (International Obesity Task Force, 2009; World Health Organization, 2010). It is well known that the habits in adult life are greatly influenced by the patterns developed during childhood. (Freedman et al., 2007). The growing epidemic of obesity among children and young people is also becoming an issue for potential adults. The problem is complex and needs to involve a systematic, multidisciplinary strategy. Worldwide professionals of health, leisure and physical education play an important role in applying responses to this issue. Innovative methods of pedagogy must be included, health and physical education systems must be more efficiently integrated, balance active lifestyle patterns should be promoted, technologies used to teach physical education should be studied, and school activities should be connected with informal community programs with help of physical education teachers. (Edginton et al., 2011).

The national health curriculum standards should encourage the preparation of curriculum for a comprehensive professional education curriculum for school health. The guidelines are designed to enhance realistic health knowledge and to identify core skills for all forms of healthy living. These techniques include analysis of the value of the actions of family, colleagues, community, media and technologies; studying how to access and use adequate health information; using communication, decision making, metrics and advocacy skills to promote health behaviour. Furthermore the efficiency and effectiveness of health education programs was correlated to an appropriate amount of time spent in health education classrooms.

There is a strong connection between school health curriculum and health literacy. Health literacy is the willingness of citizens to gain important information and services about health, to understand and to develop them. Students must develop their wellness literacy and boost their quality of life in order to accept and maintain healthy behaviour. A research study from the Institute of Medicine on health literacy states that the most effective approach to improve health literacy is to ensure that health education is a part of all educational curriculum. "The research has shown that successful school-level wellness initiatives are intense and begin before risky behaviour, according to the World Health Office (WHO) It is essential for students to obtain adequate time to obtain vital data and health education skills that are gained and improved year on year.

\section{MATERIAL AND METHODS}

Main goal: As we are aware that research work in assessment of the physical education is very limited, thus the specific aim of this work was to develop and validate a Healthy Living aspect assessment instrument, which is one of the three aspects of the physical education program: physical fitness, sports skill and neuromuscular coordination.

Procedure: According to earlier works of Alfrey, O'Connor, Phillipson, Penney, Jeanes \&t Phillipson, 2017; Cumming, Woodcock, Cooley, Holland, \& Burns, 2015, Denson \& Bowman, 2015; Perry, Nicholls, Clough, \& Crust, 2015; Richards, Gaudreault \&t Woodland, 2017; Rossato, Uphill, Swain \&t Coleman, 2016; Wang, Shen, Luo, Hu \& Garn, 2018 the process of construction and validation of the tool were performed which included: theoretical foundation, initial statement preparation, expert judgement(logical review), pilot study data collection, exploratory factor analysis (EFA) and confirmatory factor analysis (CFA). Thus the SPSS program used both mathematical methods and the PCA (version 16.0). The Jamovi program was used to execute the CFA.

Participants: Ten experts took part in logical review from field of Physical education and sports sciences with minimum of five years' experience in government or private institution. The empirical review was conducted on 600 secondary school students from government and private schools in Noida, Uttar Pradesh. 
Figure 1

\section{HEALTHY LIVING}

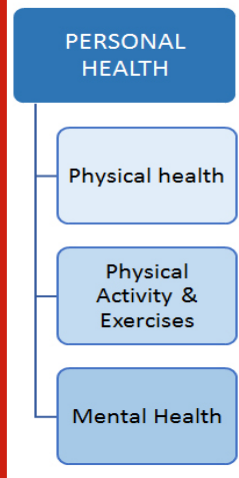

FAMILY HEALTH

Balanced Consumption of food Awareness of
diseases and preventive measures

Social

Empowerment through work Education and Action

Theoretical Foundation and Selection of variables As per the National curriculum framework, the objective of Physical education is to

Table 1. Rotated component matrix from EFA

\begin{tabular}{|l|c|c|c|}
\hline & Component & & \\
& 1 & 2 & 3 \\
\hline VAR00039 & 0.89 & & \\
\hline VAR00001 & 0.884 &. & \\
\hline VAR00040 & 0.878 & & \\
\hline VAR00002 & 0.877 & & \\
\hline VAR00011 & 0.874 &. & \\
\hline VAR00006 & 0.872 & & \\
\hline VAR00058 & 0.863 & & \\
\hline VAR00046 & 0.861 & & \\
\hline VAR00028 & 0.854 & & \\
\hline VAR00009 & 0.853 & & \\
\hline VAR00015 & 0.847 & & \\
\hline VAR00050 & 0.831 & & \\
\hline VAR00018 & 0.826 &. & \\
\hline VAR00029 & 0.814 & & \\
\hline VAR00007 & 0.809 & & \\
\hline VAR00041 & 0.809 & & \\
\hline VAR00031 & 0.806 & & \\
\hline VAR00008 & 0.797 & & \\
\hline VAR00032 & 0.725 & & \\
\hline VAR00025 & 0.669 & & \\
\hline VAR00035 & 0.653 & & \\
\hline VAR00037 & 0.623 & & \\
\hline VAR00052 & 0.605 & & \\
\hline VAR00044 & & & \\
\hline VAR00005 & & & \\
\hline VAR00024 & & 0.8631 & \\
\hline VAR00036 & & & \\
\hline VAR00056 & & & \\
\hline VAR00016 & & & \\
\hline VAR00049 & & & \\
\hline & & & \\
\hline
\end{tabular}

- Encourage children to know and embrace the obligation for safe home, school and community life, both personally and collectively,

- Allow them to consider their health condition, recognize health conditions and be told of steps to correct them.

- $\quad$ Sensitizing children to protective laws in appropriate dangerous conditions to minimize collisions and injury.

- Familiarization with first aid procedures on customary disease, injury and accidents.

Table 1. Rotated component matrix from EFA

\begin{tabular}{|c|c|c|c|}
\hline & $\begin{array}{c}\text { Component } \\
1\end{array}$ & 2 & 3 \\
\hline VAR00017 & & 0.811 & \\
\hline VAR00060 & & 0.721 & \\
\hline VAR00010 & & 0.704 & \\
\hline VAR00038 & & 0.7 & \\
\hline VAR00033 & & 0.698 & \\
\hline VAR00019 & & 0.694 & \\
\hline VAR00048 & . & 0.692 & \\
\hline VAR00026 & & 0.691 & \\
\hline VAR00021 & & 0.688 & \\
\hline VAR00053 & & 0.683 & \\
\hline VAR00013 & & 0.681 & \\
\hline VAR00051 & & 0.657 & \\
\hline VAR00003 & & 0.643 & \\
\hline VAR00047 & & 0.57 & \\
\hline VAR00055 & & & 0.802 \\
\hline VAR00022 & & & 0.74 \\
\hline VAR00004 & & & 0.733 \\
\hline VAR00043 & & & 0.722 \\
\hline VAR00014 & & & 0.721 \\
\hline VAR00030 & & & 0.717 \\
\hline VAR00034 & & & 0.697 \\
\hline VAR00023 & & . & 0.685 \\
\hline VAR00059 & & & 0.68 \\
\hline VAR00054 & & & 0.654 \\
\hline VAR00045 & & & 0.649 \\
\hline VAR00057 & & & 0.635 \\
\hline VAR00020 & & & 0.63 \\
\hline VAR00027 & & & 0.628 \\
\hline VAR00042 & & & 0.627 \\
\hline VAR00012 & & & 0.614 \\
\hline
\end{tabular}

Extraction Method: Principal Component Analysis. Rotation Method: Varimax with Kaiser Normalization. Rotation converged in 6 iterations.

Thus, the variables selected for Healthy living were Personal Health, Environmental health and Family health. As per these variables list of 90 statements were proposed involving 10 statement from each sub variables 
for assessing healthy living aspect in secondary school students.

Expert Judgement: We underwent a rational analysis to test the validation of the structure. An professional assessment was used to improve the method. To do this the ten experts from field of Physical education and sports sciences with minimum of five years' experience in government or private institution validated the statements and their belonging categories by filling the document where they had to select the categories for each statement as per their expertise provided in the form of questionnaire online at https://study.pankajapandey. com/. The statements which were selected by at least 5 experts for that particular category were select for the second version of the questionnaire and thus 90 statements were reduced to 60 statements for the further validation and pilot test.

Pilot test data collection: Throughout the pilot study, an empirical review of the statements was performed before applying the EFA (Exploratory Factor Analysis) and the CFA ( Confirmatory Factor analysis). During the process, the questionnaire including 60 statements finalized after expert review was filled by $\mathrm{N}=600$ secondary school children which is a significant no of samples for pilot study. A five-point Likert scale from one to five cumulative disagreements to consider the knowledge of secondary students with each argument was used. If the claims were closely connected to perform a factor study was checked by the KMO Sampling Calculation Adequacy and the sphericity test by Bartlett. The nearest the KMO value to 1 , the more comparable the variations in the declarations are. The high value of 0.981 , which is acceptable, was obtained from the KMO examination. The test results of the Bartlett revealed a valuable common ground between the statements ( Significance level $\mathrm{p}<.05)$, it was obtained a result of x2 (1770) = 9.98, $p=.000$. Based on these results, the data obtained from the questionnaire satisfied all the conditions for the factor analysis.

Exploratory Factor analysis: An EFA was done to categorize the statements in order to explain the internal structure of the questionnaire. The EFA was carried out using the principal component analysis process of extraction. The rotation approach used standardisation of Varimax and Kaiser, which converged into six iterations and displayed 4 major categories describing 77.67 percent of total variance. With regard to the extraction of claims, the declarations were divided into three classes or variables shown in Table 1.

To investigate the position of the item/statement, a part plot was derived from the collected data in a rotated space graph. The findings revealed the exact position of the object after rotation during the EFA, which showed that the items were strongly connected in figure 2 .

Since the current questionnaire has the same number of categories as the original category proposed (three) the layout of the categories after the EFA was different from the initial proposal. Although the number of statement selected for the final questionnaire were on the basis of the factor loading values of each statement in each category. Statement with factor loading values 0.6 or more were selected from all the three categories. For the feasibility of students and the time limitation for assessing the students in the subject only 25 statements were finalized for the questionnaire. 9 statement from component one with highest factor loading and 8 statements each from component two and three with highest factor loading were selected for the study as shown in figure 3 .

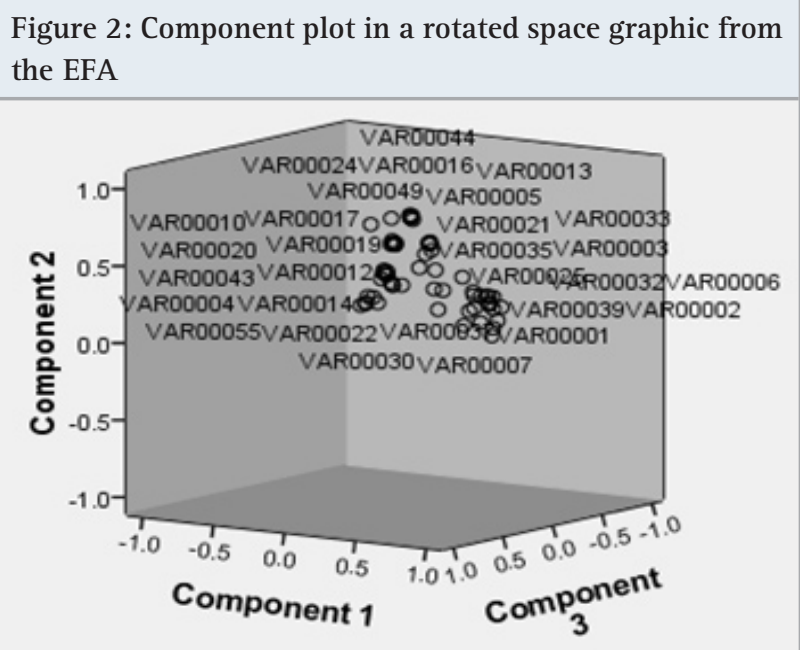

Confirmatory Factor Analysis: This method tests if the data suit into a hypothesized model of measurement. The purpose of this experiment was to prove the accuracy of the planned new distribution. In the new questionnaire, the route diagram indicated an appropriate connection between the variables (categories) and the objects investigated. (Figure 4).

The relative health indexes displayed outstanding, decent and reasonable results respectively, and results similar to the reference ranges were obtained in the IFI, TLI and CFI indices. The details then fit properly into the default delivery model.

Test for Exact Fit: $\chi^{2} \quad$ df $\quad p$

$4107272<.001$

Fit Measures:

RMSEA 90\% CI

$\begin{array}{lccll}\text { CFI } & \text { TLI } & \text { RMSEA } & \text { Lower } & \text { Upper } \\ 0.893 & 0.882 & 0.153 & 0.149 & 0.157\end{array}$

Reliability test: Finally Pearson Correlation test was conducted for reliability of the questionnaire for which the 25 statements were then converted in Multiple Choice questions (MCQ) to assess the knowledge of secondary school students about healthy living. The test retest method was then administered for the reliability of questionnaire on 60 secondary school going students. The scores from Time 1 and Time 2 were then tested for correlation by using Pearson Correlation test in order to 
evaluate the test for stability over time (Colin and Julie, 2006).The result was found to be acceptable as shown in figure 5

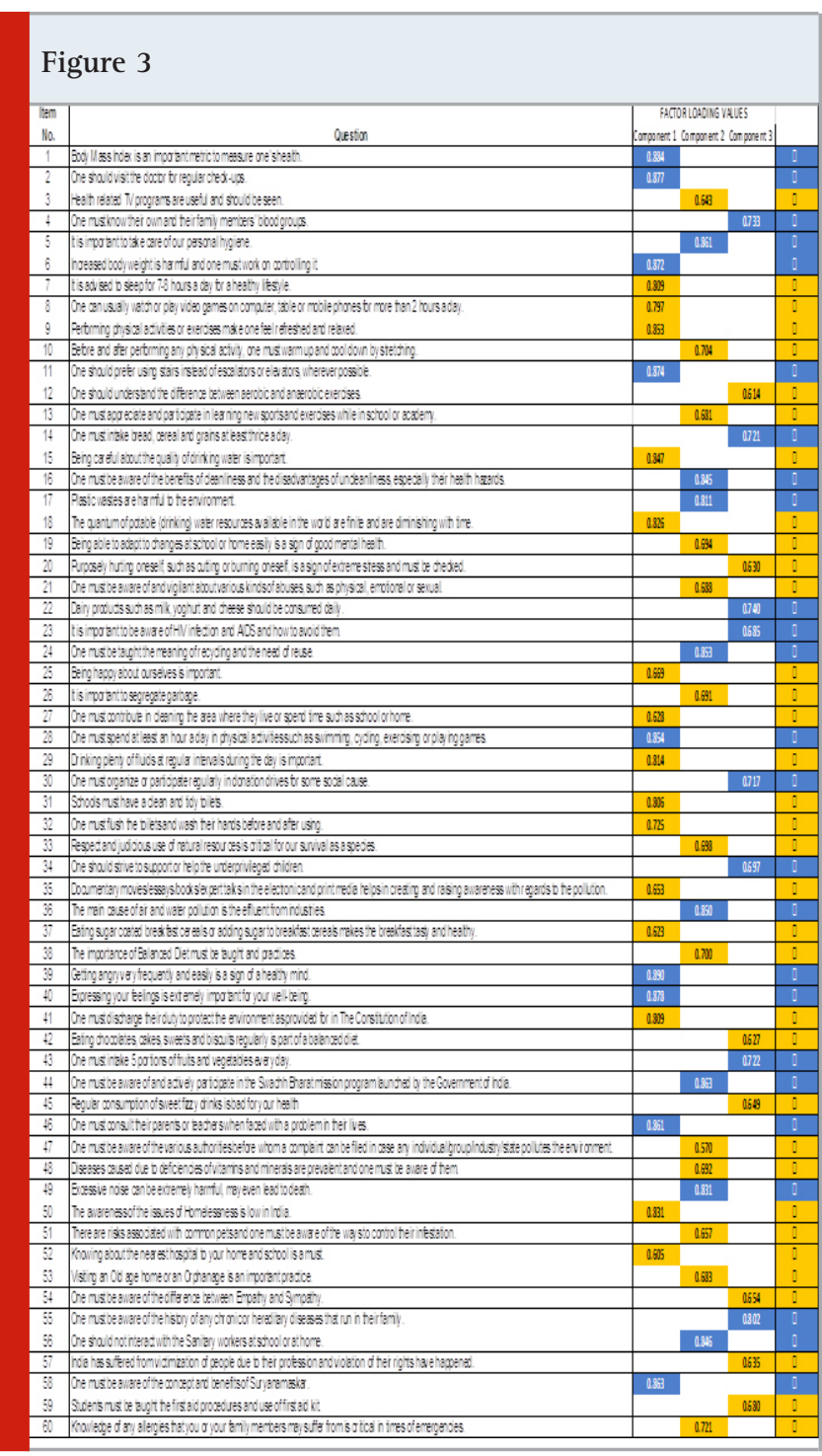

\section{DISCUSSION AND CONCLUSION}

It is important to link the benefits and results of physical education to the core learner areas of the 21st Century such as critical learning, problem solving, endurance and acceptance capability, the ability to understand and express information and the ability to act innovatively in order to continue to be valued as part of the basic school curriculum (Bailey, 2006). In the last 40 years major changes and improvements were introduced in physical education including a shift from traditional game playing for recreation to a greater focus on healthy living, wellness and lifelong physical activity (Bocarro et al., 2008; Jago et al., 2009; McKenzie \& Kahan, 2008). The importance of physical education programs are constantly being measured worldwide. Physical education initiatives need to produce evidence that will allow the profession to render curriculum interventions even more accountable. The lack of
Figure 4: Path diagram from the CFA

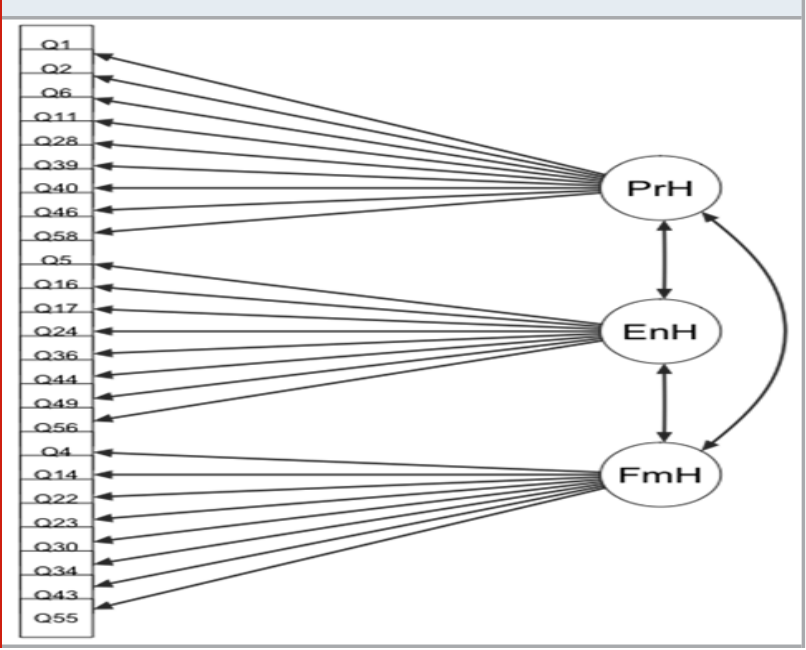

Figure 5: Correlation

\begin{tabular}{|c|c|c|}
\hline & Score1 & Score2 \\
\hline Pearson Correlation & 1 & $.987^{* *}$ \\
\hline Sig. (2-tailed) & & .000 \\
\hline N & 60 & 60 \\
\hline Pearson Correlation & $.987^{* *}$ & 1 \\
\hline Sig. (2-tailed) & .000 & \\
\hline N & 60 & 60 \\
\hline
\end{tabular}

transparency in physical education assessment programs prohibits physical education subject from being part of any community's wellness infrastructure. Quality expectations and methods of assessing the effect of physical education and its effect are the need of the present scenario in physical education.

In an increasingly structured field of schooling, the requirement for physical education program for children to show their fundamental skills is imperative. The teacher in physical education are constantly called upon to show student abilities to improve the skills to maintain an active lifestyle for wellbeing. The current study for the latest questionnaire creation on healthy living will lead to increase the standard and quality of physical education assessment. All the criteria for development of standardized questionnaire of were followed to establish a structured questionnaire that improves the importance of the questionnaire and makes sure a broad variety of implementations are included. In order to ensure good accuracy, validity and interpretation of the variables in the questionnaire and the right association of 
characteristics, the filtering method was performed using expert evaluations. The suitability of the questionnaire, and the apt feature selection to determine the healthy living aspect of Physical Education, is reaffirmed considering the decrease in the number of items and the modifications did not alter the import of the original proposal.

The excellent results from the pilot test statistically strengthened the theoretical foundation for the questionnaire and provided excellent reliability values for the Cronbach alpha test, without substantial changes in deletion of the statements. The KMO and Bartlett resulted in excellent results and significant results, which revealed that the statements were strongly related and was suitable for factor analysis. The EFA of the questionnaire structure established the grouping of the items into three classes aligned to the initial (curricular) approach, which led to little distinction from the original proposal. Without some significant changes from the first edition, the latest delivery was easy to understand and validated the structure of the questionnaire. In comparison, the reliability requirements were high for the new groups. The CFA has further analysed the composition of the questionnaire and the results proved sufficient relations between statements and variables. The absolute, incremental and relative fit indices were excellent, efficient and sufficient results for both the -2/df, RMSEA and RMR tests; hence the data were considered to be in accordance with the distribution questionnaire. Finally, the Pearson correlation test has demonstrated that there was a strong correlation between the statements of questionnaire.

To conclude, a precious questionnaire was developed and tested to evaluate the healthy living aspect of physical education in secondary school students and to serve the original intent of this work. This developed tool is valuable for assessment of physical education and contribute in assessing the knowledge of healthy living among children studying in secondary schools.

\section{REFERENCES}

Alfrey, L., O’Connor, J., Phillipson, S., Penney, D., Jeanes, R., \&t Phillipson, S. (2017). Attitudes of pre-service physical education teachers to healthism: Development and validation of the Attitude Towards Healthism Scale (ATHS). European Physical Education Review, 1-15. http://doi.org/10.1177/1356336X17742665

Allensworth D, Wyche J, Lawson E, Nicholson L eds. Committee on Comprehensive School Health Programs, Division of Health Science Policy, Institute of Medicine. Defining a comprehensive school health program: An interim statement; 1995. National Academy Press: Washington, D.C.

Bailey, R. (2006). Physical education and sport in schools: A review of benefits and outcomes. Journal of School Health, 76(8), 397-401.

Bocarro, J., Kanters, M. A., Casper, J., \& Forrester, S. (2008). School physical education, extracurricular sports and lifelong active living. Journal of Teaching of Physical Education, 27,155-166.

Capella-Peris, C., Gil-Gómez, J., \&t Chiva Bartoll, Ò. (2018). A rubric to assess the teaching competency using motor skills and body language games: Initial development and validation.

Comrey, A. L. (1978). Common methodological problems in factor analytical studies'. Journal of Consulting and Clinical Psychology, 46(4), 648-659. http://doi. org/10.1037/0022-006X.46.4.648

Cronbach, L. J. (1951). Coefficient alpha and the internal structure of tests. Psychometrika,16(3),297-334.http:// doi.org/10.1007/BF02310555

Cronbach, L. J., \&t Meehl, P. E. (1955). Construct validity in psychological tests. Psychological Bulletin, 52(4), 281-302. http://doi.org/10.1037/h0040957

Cumming, J., Woodcock, C., Cooley, S. J., Holland, M. J. G., \& Burns, V. E. (2015). Development and validation of the groupwork skills questionnaire (GSQ) for higher education. Assessment \& Evaluation in Higher Education, 40(7), 988-1001. http://doi.org/10.1080/026 02938.2014.957642

Denson, N., \&t Bowman, N. (2015). The development and validation of an instrument assessing studentinstitution fit. Assessment \& Evaluation in Higher Education, 40(8), 1104-1122. http://doi.org/10.1080/02 602938.2014.970513

Edginton, C., Chin, M. K., \&t Bronikowski, M. (2011). Health and physical education: a new global statement of consensus (from a Polish perspective). Biomedical Human Kinetics, 3(1), 44-48.

Edginton, C.R., Kirkpatrick, B., Schupach, R., Philips, C., Chin, M.K., \&t Chen, P. (2011). A dynamic pedagogy of physical education teacher preparation: Linking practice with theory. Asian Journal of Physical Education and Recreation, 16(2), 7-23.

Freedman, D. S., Mei, Z., Srinivasan, S. R., Berenson, G. S., \& Dieta, W. H. (2007). Cardiovascular risk factors and excess adiposity among overweight children and adolescents: The Bogalusa heart study. Journal of Pediatrics, 150, 12-17.

Hennessy, B. 1996. Physical Education Sourcebook. Champaign (IL): Human Kinetics.

Hoyle, R. H. (1995). Structural equation modeling: Concepts, issues, and applications. London: Sage. http:// doi.org/10.1080/1091367X.2014.952370

International Obesity Task Force. (2009). Obesity: Understanding and challenging the global epidemic. 2009- 2010 report. Retrieved February 13, 2011, from http://www.iaso.org/site_media/uploads/ IASO_ Summary_Report_2009.pdf.

Jago, R., McMurray, R. G., Bassin, S., Pyle, L., Bruceker, S., Jakicic, J. M., Moe, E., Murray, T., \&t Volpe, S. L. (2009). Modifying middle school physical education: Piloting strategies to increase physical activity. Pediatric Exercise Science, 21(2), 171-185.

Joint Committee on National Health Education 
Standards. (1995). Achieving health literacy: An investment in the future. Atlanta, GA: American Cancer Society.

Joint Committee on National Health Standards. National Health Education Standards: Achieving Excellence. American Cancer Society; 2007.

Kidd, B., and P. Donnelly, 2000. Human rights in sport. International Review for the Sociology of Sport, Vol. 35, No. 2, pp. 131-148.

Kline, R. (2005). Principles and practice of structural equation modeling (3rd ed.). New York, NY: The Guildford Press.

Lund, J. L., \&t Kirk, M. F. (2010). Performance-based assessment for middle and high school physical education. Champaign, IL: Human Kinetics.

McKenzie, T., \&t Kahan, D. (2008). Physical activity, public health, and elementary schools. The Elementary School Journal, 108(3), 171-179.

Modelling. Measurement in Physical Education and Exercise Science, 19(1), 12-21.

Moss, T., Landon, T. J., Fleming, A. (2017). Sports and Disability: Enhanced Health, Self-Efficacy, and Social Inclusion Through Athletic Participation, Review of Disability Studies, Vol. 13, No. 3

Pearson, K. (1948). Early Statistical Papers. Cambridge: University Press.
Perry, J. L., Nicholls, A. R., Clough, P. J., \&t Crust, L. (2015). Assessing Model Fit: Caveats and Recommendations for Confirmatory Factor Analysis and Exploratory Structural Equation

Richards, K. A. R., Gaudreault, K. L., \&t Woods, A. M. (2017). Understanding physical educators' perceptions of mattering: Validation of the Perceived Mattering Questionnaire - Physical Education. European Physical Education Review, 23(1), 73-90.http://doi. org/10.1177/1356336X16637320

Rossato, C. J. L., Uphill, M. A., Swain, J., \& Coleman, D. A. (2016). The development and preliminary validation of the Challenge and Threat in Sport (CAT-Sport) Scale. International Journal of Sport and Exercise Psychology, 1-14. http://doi.org/10.1080/1612197X.2016.1182571

Veal, M. L. (1995). Assessment as an instructional tool. Strategies, 8(6),10-15. Anderson, A., \&t Goode, R. (1997). Assessment informs instruction. Journal of Physical Education, Recreation \& Dance, 68 (3), 42-49.

Wang, J., Shen, B., Luo, X., Hu, Q., \&t Garn, A. C. (2018). Validation of a Teachers' Achievement Goal Instrument for Teaching Physical Education. Journal of Teaching in Physical Education, 37(1), 91-100. http:// doi.org/10.1123/jtpe.2016-0210

World Health Organization. Information series on school health: Skills for health; 2003. Retrieved June 3, 2007 